\title{
Experimental investigations on cylindrical latent heat storage units with sodium acetate trihydrate composites utilizing supercooling
}

Dannemand, Mark; Johansen, Jakob Berg; Kong, Weiqiang; Furbo, Simon

Published in:

Applied Energy

Link to article, DOI:

10.1016/j.apenergy.2016.05.144

Publication date:

2016

Document Version

Peer reviewed version

Link back to DTU Orbit

Citation (APA):

Dannemand, M., Johansen, J. B., Kong, W., \& Furbo, S. (2016). Experimental investigations on cylindrical latent heat storage units with sodium acetate trihydrate composites utilizing supercooling. Applied Energy, 177, 591601. https://doi.org/10.1016/j.apenergy.2016.05.144

\section{General rights}

Copyright and moral rights for the publications made accessible in the public portal are retained by the authors and/or other copyright owners and it is a condition of accessing publications that users recognise and abide by the legal requirements associated with these rights.

- Users may download and print one copy of any publication from the public portal for the purpose of private study or research.

- You may not further distribute the material or use it for any profit-making activity or commercial gain

- You may freely distribute the URL identifying the publication in the public portal 
Title: Experimental investigations on cylindrical latent heat storage units with sodium acetate trihydrate composites utilizing supercooling Authors: Mark Dannemand, Jakob Berg Johansen, Weiqiang Kong, Simon Furbo Corresponding email: markd@byg.dtu.dk Affiliation: Department of Civil Engineering, Technical University of Denmark, Brovej 118, Kgs. Lyngby, DK 2800, Denmark

\begin{abstract}
Latent heat storage units utilizing stable supercooling of sodium acetate trihydrate (SAT) composites were tested in a laboratory. The stainless steel units were $1.5 \mathrm{~m}$ high cylinders with internal heat exchangers of tubes with fins. One unit was tested with $116 \mathrm{~kg}$ SAT with 6\% extra water. Another unit was tested with $116.3 \mathrm{~kg}$ SAT with $0.5 \%$ Xanthan rubber as a thickening agent and $4.4 \%$ graphite powder. The heat exchange capacity rate during charge was significantly lower for the unit with SAT and Xanthan rubber compared to the unit with SAT and extra water. This was due to less convection in the thickened phase change material after melting. The heat content in the fully charged state and the heat released after solidification of the supercooled SAT mixtures at ambient temperature was higher for the unit with the thickened SAT mixture. The heat discharged after solidification of the supercooled SAT with extra water decreased over the charge and discharge cycles while the heat discharged from the SAT with Xanthan rubber remained stable. In both units, the solidification started spontaneously in the majority of the test cycles. This was due to the design of the unit or the method for handling the expansion and contraction of the SAT during charge and discharge.
\end{abstract}

Keywords: Compact Thermal Energy Storage; Latent Heat; Phase Change Material; Sodium Acetate Trihydrate; Supercooling.

\title{
1. Introduction
}

Large amounts of energy are used for heating of buildings. A significant part of the energy used to cover these demands comes from fossil fuels. The burning of fossil fuels leads to climate change and other pollution. Clean energy free from greenhouse gas emissions can be produced by renewable resources such as solar. Solar irradiance can be harvested by solar collectors as thermal energy and used for heating purposes. The supply of solar energy is however intermittent and does often not meet demand patterns. Thermal energy storage is therefore needed as parts of solar heating systems to match the intermittent supply of solar energy with varying demands.

Phase change materials (PCM) can be used to improve the volumetric storage capacity of a thermal energy storage compared to sensible heat storage by utilizing the latent heat of fusion [1], [2], [3]. Sodium acetate trihydrate (SAT) is an incongruently melting salt hydrate with a latent heat of fusion of $264 \mathrm{~kJ} / \mathrm{kg}$ at the melting point of $58{ }^{\circ} \mathrm{C}$ [4]. These thermal properties make SAT a suitable material to integrate with solar heating systems, space heating and domestic hot water preparation. Furthermore, melted SAT has the ability to cool down to ambient temperatures without crystalizing [5]. Letting the SAT remain in this supercooled state allows for a partly loss-free storage, when the latent heat of fusion of the SAT is stored in temperature equilibrium with the ambient. Solidification of the supercooled SAT can be initiated when a heat demand arises and the latent heat of fusion is released and used for the heating purpose. 
This principle of utilizing stable supercooling makes compact seasonal heat storage possible in decentralized systems for example in single family houses [6].

\subsection{State of the art}

A lot of research has previously been carried out aiming to find solutions for improving the performance of thermal energy storage. López-Navarro et al. did an experimental characterization of a PCM storage tank with paraffin [7]. Novo et al. did a review on large seasonal sensible heat storage [8]. Nkwetta and Haghighat did a review on available technologies including active systems for thermal energy storage with PCMs [9]. Sharif et al. likewise did a review on applications with PCMs for space heating and domestic hot water preparation [10]. None of these reviews included technologies that utilize supercooling of a PCM. Xu et al. [11] and Pinel et al. [12] did reviews on methods and available technologies for seasonal thermal energy storage and briefly touch on the concept of utilizing supercooling of SAT for compact seasonal heat storage. Persson and Westermark did an analysis of the economy of buildings with seasonal thermal energy storage and found that their relative competitiveness was higher when used for passive houses compared to houses with higher heat demands [13]. Colclough and McGrath did life cycle analysis of a low energy dwelling and found that over a long-term perspective, a solar combi-system with seasonal thermal energy storage had the lowest embodied energy and carbon [14].

Dannemand et al. presented in an article a number of practical solutions to barriers and problems for obtaining a functional heat storage based on stable supercooling of SAT [15]. They also describe how this concept can be used for seasonal heat storage of solar thermal energy.

\subsection{Sodium acetate trihydrate composites}

Phase separation is a key problem when using the incongruently melting SAT as a heat storage material. Melted SAT consists of sodium acetate dissolved in water [16]. The solubility of the sodium acetate is too low in the supercooled state to dissolve all the salt in the water from the melted SAT. Undissolved sodium acetate will therefore settle to the bottom of the container. All the potential SAT crystals cannot be formed when the SAT solidifies again due to the physical separation of the segregated sodium acetate at the bottom and the corresponding water in the top of the container [17]. This reduces in practice the latent heat of fusion and the heat storage potential [18]. One suggested solution for solving this problem has been adding extra water to the SAT. In this way all the sodium acetate can be dissolved in water [19]. Adding extra water to the PCM mixture will however reduce the heat storage capacity compared to SATs potential [20].

Another possible solution is adding a thickening agent to the SAT. The precipitated sodium acetate will then stay suspended in the thickened supercooled solution and will not settle to the bottom. In this case the sodium acetate can recombine with the nearby water molecules at crystallization to form SAT [21]. However, the heat transfer in a PCM storage is affected by the convection in the PCM as elucidated by Sun et al. and may be reduced when the viscosity increases [22]. Ryu et al. investigated several thickening agent for different salt hydrates [23]. Several authors found that an SAT composite with carboxymethyl cellulose (CMC) was stable through thermal cycling [24], [25], [26]. Meisingset and Grønvold suggested using Xanthan rubber as a thickening agent [21]. All of these investigations were on a small laboratory scale and not tested on a scale representing heat storage applications large enough to meet a heat demand of a single family house.

In laboratory experiments Dannemand et al. characterized the performance of two flat storage units with approximately $200 \mathrm{~kg}$ SAT mixtures, one with extra water and another with CMC [27], [28]. The tested units had an 
internal height of the PCM chamber of $5 \mathrm{~cm}$. The low height was to reduce the risk of phase separation. Higher units may result in aggravated phase separation but with fewer design restrictions. They found that the heat content was reduced over repeated charge and discharge cycles for the unit with SAT and extra water but it was stable for the unit with SAT and CMC. They also found that the heat exchange capacity rate was lower in the unit with the thickened SAT mixture.

\subsection{Heat transfer}

The heat transfer of a PCM storage unit is highly affected by the design of the heat exchanger. Different designs were evaluated by Medrano et al [29]. Chiu and Martin investigated numerically and experimentally the performance of a finned heat exchanger heat storage unit [30]. The low thermal conductivity of PCMs is another typical challenge of using PCMs in heat storage [31]. This combined with no heat transfer by convection when the PCM is in solid state and limited heat transfer by convection in a melted PCM with high viscosity, may result in a low heat exchange capacity rate (HXCR) in a PCM storage [32].

It was shown by Dannemand et al. through numerical simulations that the HXCR of a PCM storage had a significant impact on the system performance of a solar combi-system including a PCM storage utilizing supercooling [15].

As the thermal conductivity of the PCM in a store affects the HXCR, improvement of the thermal conductivity of PCMs has been investigated by several researchers. Enhancing the thermal conductivity of PCMs has for example been done by adding expanded graphite to the PCMs [26], [31] or by impregnating graphite matrixes with the PCM [33], [34]. Zhang et al. did a review on fabrication and characterization of composite PCMs for performance enhancement [35]. Dannemand et al. investigated the effect on the thermal conductivity by adding graphite powder or graphite flakes to thickened SAT composites [36]. Dannemand et al. also suggest adding oil to the PCM chamber to increase heat transfer as the oil could fill in insulating cavities in the solid PCM [15]. Cavities in the PCM will be formed due to the density difference between the solid and liquid SAT.

\subsection{Scope}

The performance of $1.5 \mathrm{~m}$ high heat storage unit with SAT and extra water utilizing supercooling has not previously been reported. The performance of SAT thickened with Xanthan rubber in real application sized units has not previously been reported. Furthermore, the effect of adding oil to the PCM chamber to increase heat transfer, which is touched on in this article has not been reported previously.

The performances of two $1.5 \mathrm{~m}$ high cylindrical heat storage units containing SAT with extra water or SAT with Xanthan rubber and graphite powder are characterized. The performance of the units when actively utilizing supercooling for long term heat storage has been elucidated. Also, the performance of a storage unit containing water is compared to the performance of a unit containing SAT with extra water in terms of heat content and HXCR. The size of the investigated units could be for an actual application in heating systems for a single family house if multiple units are installed. The heat exchange capacity rates of the storage units, heat contents over repeated cycles, the stability of the supercooling and the energy discharged after the supercooled periods has been measured and analysed.

\section{Method}

Laboratory tests were carried out with heat storage units containing water and the two different SAT composites. 


\subsection{Storage unit description}

The heat storage units were designed as stainless steel cylinders to be placed vertically. The cylinders were $150 \mathrm{~cm}$ high with a diameter of $30 \mathrm{~cm}$. The units were insulated with $4 \mathrm{~cm}$ expanded polypropylene during testing. One of the two units had inspection windows to visually observe the PCM inside the unit during operation, (see Figure 1).

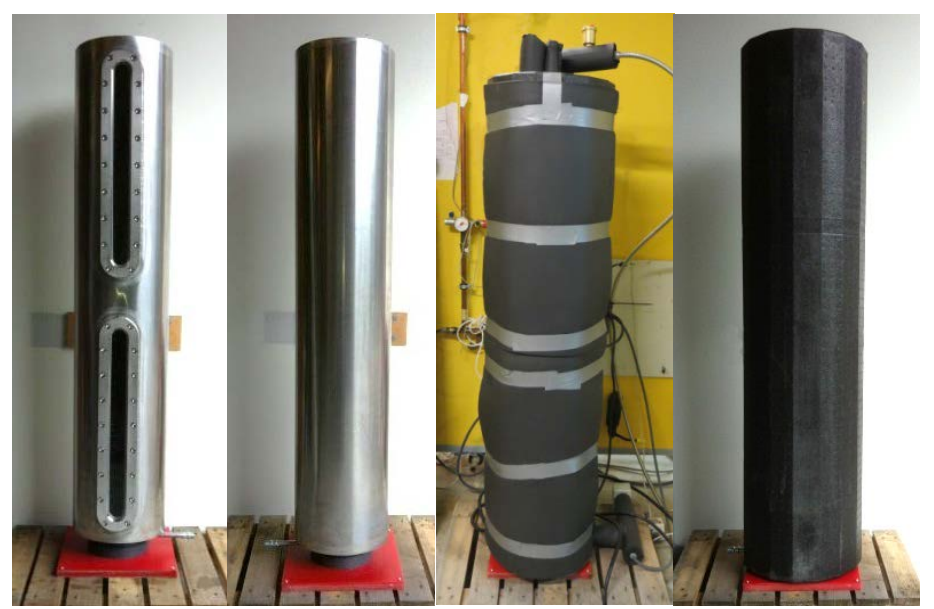

Figure 1. Cylindrical heat storage units with and without inspection windows and insulation.

Internal heat exchangers consisted of 16 stainless steel pipes located in a circular formation in the length of the cylinder with thin aluminium plates attached as fins to increase the heat transfer. The distance between the aluminium plates was approximately $0.5-1 \mathrm{~cm}$ (see Figure 2). Manifolds with inlets and outlets were located on the top and bottom of the cylinder, see Figure 3.

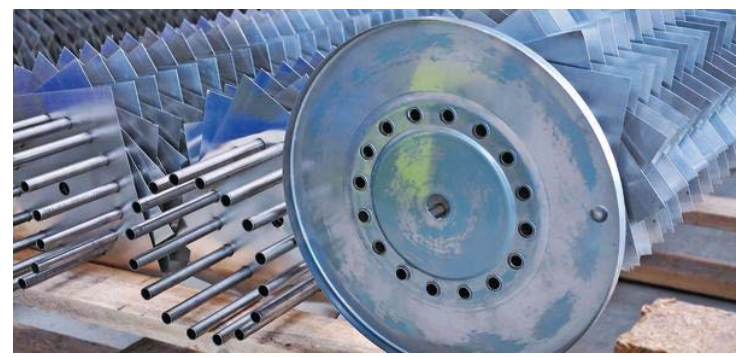

Figure 2. Internal heat exchanger [37].

The units were filled approximately $90 \%$ with the storage mediums leaving an air gap in the top of the cylinder to accommodate the expansion/contraction of the PCM during heating and cooling (see Figure 3). In some tests, an air filter was installed either directly on the top of the tank or at the end of a tube connected to the PCM chamber. This was to allow for the PCM to expand/contract without pressure build-up in the PCM chamber while limiting the possibility of airborne particles to enter and disturb the stability of the supercooling. During heating when the PCM expanded, some of the air in the top of the PCM chamber was pushed out to the ambient through the air filter keeping ambient pressure in the PCM chamber. During cooling and contraction of the PCM, air was sucked into the chamber through the air filter while particles in the air were filtered out, still keeping ambient pressure inside the PCM chamber. In other tests, the top of the PCM chamber was connected to an external expansion tank without prepressure via a tube, hence having a closed PCM chamber where the PCM could expand with reduced pressure buildup. Water vapour could possibly escape from the unit when the air filter was installed, whereas this was avoided with 

achieve stable supercooling of SAT in a steel chamber [15][28].

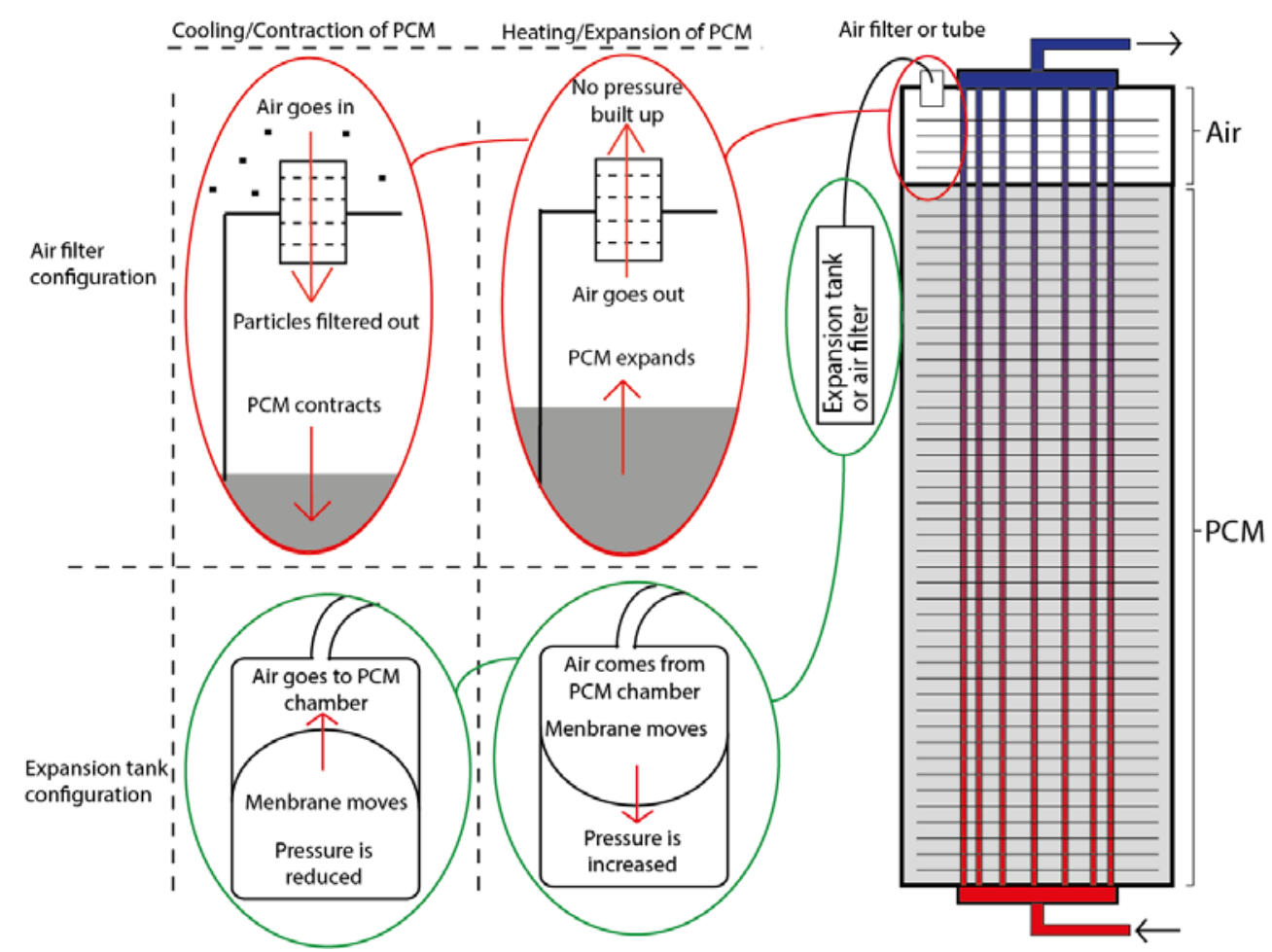

Figure 3. Diagram of cylindrical heat storage unit and heat exchanger.

The thermal capacity of the unit without the water or PCM $C_{\text {tank }}$ was estimated to be $27.3 \mathrm{~kJ} / \mathrm{K}$ for the unit without inspection windows and $40 \mathrm{~kJ} / K$ for the unit with inspection windows. These were determined by considering the masses and the materials of the empty units as well as the heat transfer fluid in the heat exchangers.

\subsection{Storage materials}

Water has often been used as the storage medium for short term storage and has therefore been tested as reference material for comparison with the PCMs. The heat storage unit with inspection windows was initially tested with water. Afterwards it was tested with a composite of 93.6\% SAT and 6.4\% extra water (SATH2O), equivalent to 56.5\% sodium acetate and $43.5 \%$ water. All percentages are by weight. The other unit was tested with a mixture of $95.1 \%$ SAT, $0.5 \%$ Xanthan rubber as a thickening agent and $4.4 \%$ fine graphite powder for enhancing the thermal conductivity of the PCM (SATXC).

The PCM composites were prepared by melting the SAT in a closed barrel in a large oven. After melting the SAT, water or graphite was mixed into the barrel. The Xanthan rubber powder was mixed with 2-3 kg solid crushed SAT before it was added to the melted SAT little-by-little while stirring the melted PCM composite with a mortar mixer. This was done to ensure that the Xanthan rubber was properly dispersed in the mixture. The mixing of SAT with Xanthan rubber was done with a moderate intensity as the PCM mixture became a thick jelly even at high temperatures and air bubbles were easily trapped in the PCM. Air trapped in the PCM will reduce storage density and reduce heat transfer in the PCM. 
Charging and discharging cycles were carried out with the units filled with $91 \mathrm{~kg}$ water, $116 \mathrm{~kg}$ SATH2O and $116.3 \mathrm{~kg}$ SATXC. With a density of SAT of $1280 \mathrm{~kg} / \mathrm{m}^{3}$ in liquid phase [38], all units were filled with approximately the same volume for all mediums.

\subsection{Test cycles and test setup}

The heat storage units were connected, via a pipe loop with water as the heat transfer fluid, to an electric heating element with a power of 3, 6 or $9 \mathrm{~kW}$ for charging and to a central cooling unit for discharging via a heat exchanger. The inlet temperature of the heat transfer fluid during discharge was controlled with a thermostatic valve controlling the flow on the heat sink side of the heat exchanger, see Figure 4.

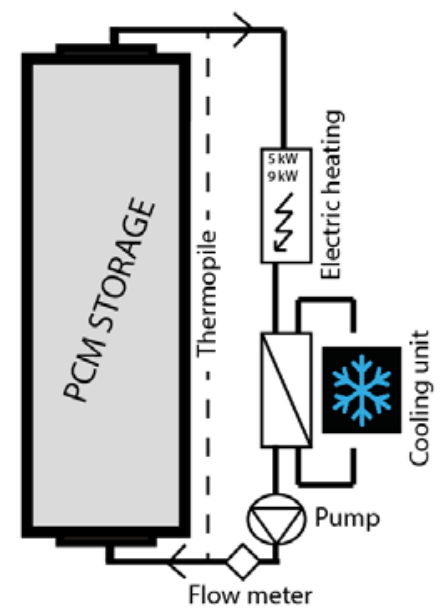

Figure 4. Schematic of charge and discharge loop for the PCM storage.

The flow direction through the unit was from bottom to top for both charge and discharge. During charging the thermostat of the electric heating element was set to $90-95^{\circ} \mathrm{C}$. During discharge, the inlet temperature was set to be $20-25^{\circ} \mathrm{C}$.

Six test cycles were carried out with water and 17 test cycles with SATH2O as the storage medium in the unit with inspection windows. A total of 40 test cycles were carried out with the unit with SATXC without inspection windows.

After the first 10 test cycles, 0.5 litres of paraffin oil was added to the PCM chamber of the unit with SATXC. After a number of test cycles, additional paraffin oil was added to the PCM chamber in steps until a total of 1.5 litre paraffin oil had been added. This was done as an attempt to enhance the heat transfer in the PCM. The oil is meant to float on top of the liquid state PCM due the density difference and the fact that the liquids do not mix. When the SAT solidifies and contracts the oil is then sucked into the PCM instead of air. This may enhance the effective heat transfer of the PCM mixture as the cavities filled with oil will provide less thermal resistance compared to cavities with air.

A five junction thermopile based on copper/constantan type-TT thermocouples with counter flow sensors inside the inlet and outlet pipes measured the temperature difference across the inlet and outlet. The absolute flow temperatures were measured with thermocouples. All thermocouples were copper/constantan type- $T$ with an accuracy of $0.5 \mathrm{~K}$. The accuracy of the temperature difference measured by the thermopile was $0.1 \mathrm{~K}$. Temperatures on the outside of the tank were measured with 1 thermocouple on the bottom outer surface, 5 thermocouples distributed evenly on the outer side of the tank wall inside the insulation. A glass rod with 5 thermocouples evenly 
distributed in the height of the tank measured the temperatures in the centre of the unit with inspection windows. One thermocouple measured the ambient temperature. The flow rate was measured at the inlet with a Cloruis flow meter which had been calibrated to have an accuracy of $\pm 1 \%$ in the relevant flow range. Solartron cards with a PC were used to log the measurements.

\subsection{Calculations}

The charge power $\dot{Q}_{\text {charge }}[\mathrm{W}]$ and discharge power $\dot{Q}_{\text {discharge }}[\mathrm{W}]$ were determined by:

$\dot{Q}_{\text {charge/discharge }}=\dot{V} \cdot c_{p} \cdot \rho \cdot\left(T_{i}-T_{o}\right)$

where, $T_{i}$ is the inlet temperature, $T_{o}$ is the outlet temperature, $\dot{V}$ is the volume flow rate of the heat transfer fluid measured at the inlet, $c_{p}$ is the specific heat capacity of the heat transfer fluid at mean temperature between $T_{i}$ and $T_{o}, \rho$ is the density of the heat transfer fluid at $T_{i}$.

The heat loss coefficients $H_{\text {loss }}[\mathrm{W} / \mathrm{K}]$ of the storage units were determined by heating the units to a stable temperature over a long period. The heat balance of the system was then used to determine the heat loss experimentally i.e. the heat added to the system was equal to the heat loss. In this way a simplified heat loss coefficient with a constant value was determined by:

$$
H_{\text {loss }}=\dot{Q} /\left(T_{s}-T_{a m b}\right)
$$

where $T_{s}$ is the mean temperature of the surface sensors and $T_{a m b}$ is the ambient temperature. The heat loss coefficient for the storage unit was used when calculating the heat content of the storage based on the measured data. The heat content in the storage unit after a charge $E_{\text {charge }}[\mathrm{J}]$ or the heat discharged from the unit $E_{\text {discharge }}[\mathrm{J}]$ over a specific time period $t$ was determined by:

$E_{\text {charge } / \text { discharge }}(t)=\int_{0}^{t}\left(\dot{Q}-H_{\text {loss }} \cdot\left(T_{s}-T_{\text {amb }}\right)\right) d t$

where $T_{s}$ and $T_{a m b}$ are for the relevant time steps. The heat content of the PCM per mass at a specific storage temperature $T_{s}$ above a defined start temperature $T_{\text {start }}$ excluding the specific heat of the tank material and heat transfer fluid $C_{\text {tank }}$ was calculated by the following expression:

$E_{P C M}\left(T_{s}, T_{\text {start }}\right)=\frac{E_{\text {charge } / \text { discharge }}\left(T_{s}, T_{\text {start }}\right)-C_{\text {tank }} \cdot\left(T_{s}-T_{\text {start }}\right)}{m}$ where $E_{\text {charge/discharge }}\left(T_{s}, T_{\text {start }}\right)$ is the measured heat content of the unit at a temperature $T_{s}$ above a start temperature $T_{\text {start }}$ and $m$ is the mass of the PCM. This allows for comparing the heat content of the different PCMs disregarding the heat capacities of the units and comparing the measurement to a theoretical storage capacity of the PCMs with given sensible and latent heats.

The heat exchange capacity rate was expressed by the following equation, which can be derived from the heat transfer rate and log mean temperature difference [39], [40].

$H X C R=\dot{V} \cdot c_{p} \cdot \rho \cdot \ln \left(\frac{T_{i}-T_{S}}{T_{o}-T_{S}}\right)$ 


\subsection{Material properties}

211 Dannemand et al. described the theoretical heat content of supercooled SAT with melting at a specific temperature [15]. This approach has been adapted for the SATXC mixture. The specific heat capacity for the solid and liquid SATXC was estimated to be $2.0 \mathrm{~kJ} / \mathrm{kg} \mathrm{K}$ and $3.1 \mathrm{~kJ} / \mathrm{kg} \mathrm{K}$, similar to SAT [41]. The latent heat of fusion of the SATXC mixture was estimated to be $251 \mathrm{~kJ} / \mathrm{kg}$ at the melting point of $58^{\circ} \mathrm{C}$, which is equivalent to $95.1 \%$ of the heat of fusion of SAT [4]. The theory of Furbo and Svendsen has been adapted to the SATH2O mixture to describe the theoretical heat content of SATH2O as a function of temperature [19]. Adding extra water to SAT affects the melting behaviour of the SATwater mixture and reduces the latent heat of fusion of the PCM mixture as some SAT dissolves in the extra water. The melting takes place over a temperature range when extra water is added to SAT. The specific heat capacities for solid and liquid SATH2O were estimated to be $2.1 \mathrm{~kJ} / \mathrm{kg} \mathrm{K}$ and $3.2 \mathrm{~kJ} / \mathrm{kg} \mathrm{K}$ using the correlation of Araki [41]. Figure 5 shows the theoretical heat content of SATH2O and SATXC per mass as a function of the temperature from $20-90{ }^{\circ} \mathrm{C}$. The heat contents in the supercooled states were estimated by extrapolating the lines representing the sensible heats in the melted states down to $20^{\circ} \mathrm{C}$. The dotted lines represent the heat contents in the supercooled states. The loss-free storage potential for storage at an ambient temperature of $20^{\circ} \mathrm{C}$ is marked.

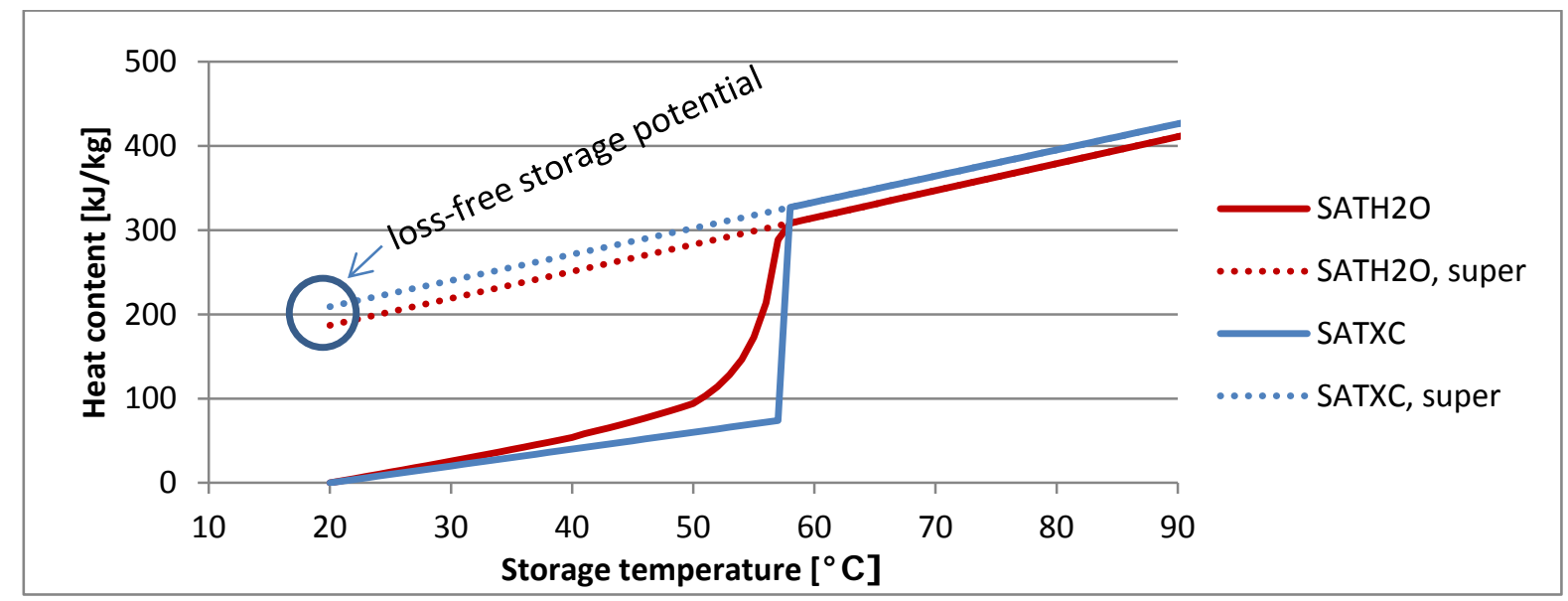

Figure 5. Theoretical heat content and storage potential of SATH2O and SATXC as a function of temperature.

The measured heat content per mass of the PCM calculated by equation (4) was compared to the theoretical heat content displayed in Figure 5. The PCM temperature was assumed to be the measured storage temperature. The measured storage temperatures may deviate from the actual PCM temperatures due to temperature gradients in the PCMs during charge and discharge. This was especially the case when the storage temperature was measured only on the outer surface of the tank. This caused either an overestimation or underestimation of the PCM temperature during charge and discharge. At the hot state and at the supercooled state where the temperatures were stable over a period of time, it was assumed, that the PCM temperatures were uniform in the storage unit and the temperatures were accurately measured by the sensors.

\section{Results and discussions}

Comparisons of the HXCRs, heat contents, and charge and discharge powers of the units with the three different storage mediums were made with various flow rates. 


\subsection{Charge}

Charging the unit filled with water was compared to charging the unit filled with SATH2O. The temperatures of the units before and after charging, the flow rates, heating element powers, inlet temperatures, the heat contents of the stores and the time for the full charges are listed in Table 1. The units were considered fully charged when the average storage temperatures were $0.5 \mathrm{~K}$ below the temperature at the stable hot states.

Table 1. Start and max storage temperature, flow rate, heating element power, inlet temperature, heat content and charge time for units with water and SATH2O.

\begin{tabular}{|l|c|c|c|c|c|c|}
\hline $\begin{array}{l}\text { Storage } \\
\text { medium }\end{array}$ & $\begin{array}{c}\text { Start temp. } \\
T_{\text {start }}\end{array}$ & $\begin{array}{c}\text { Max temp. } \\
T_{\max }\end{array}$ & $\begin{array}{c}\text { Flow rate } \\
\dot{V}\end{array}$ & $\begin{array}{c}\text { Heating element } \\
\dot{Q} / T_{\text {in }}\end{array}$ & $\begin{array}{c}\text { Heat content } \\
E_{\text {storage }}\end{array}$ & $\begin{array}{c}\text { Charge time } \\
t\end{array}$ \\
\hline Water & $17.5^{\circ} \mathrm{C}$ & $85.5^{\circ} \mathrm{C}$ & $7.2 \mathrm{I} / \mathrm{min}$ & $9 \mathrm{~kW} / 87^{\circ} \mathrm{C}$ & $28.6 \mathrm{MJ}$ & $128 \mathrm{~min}$ \\
\hline SATH2O & $15.0^{\circ} \mathrm{C}$ & $87.4^{\circ} \mathrm{C}$ & $7.3 \mathrm{I} / \mathrm{min}$ & $9 \mathrm{~kW} / 89^{\circ} \mathrm{C}$ & $50.1 \mathrm{MJ}$ & $292 \mathrm{~min}$ \\
\hline
\end{tabular}

Figure 6 shows the HXCR and power $\dot{Q}_{\text {charge }}$ over the charge period for the units filled with water and SATH2O.

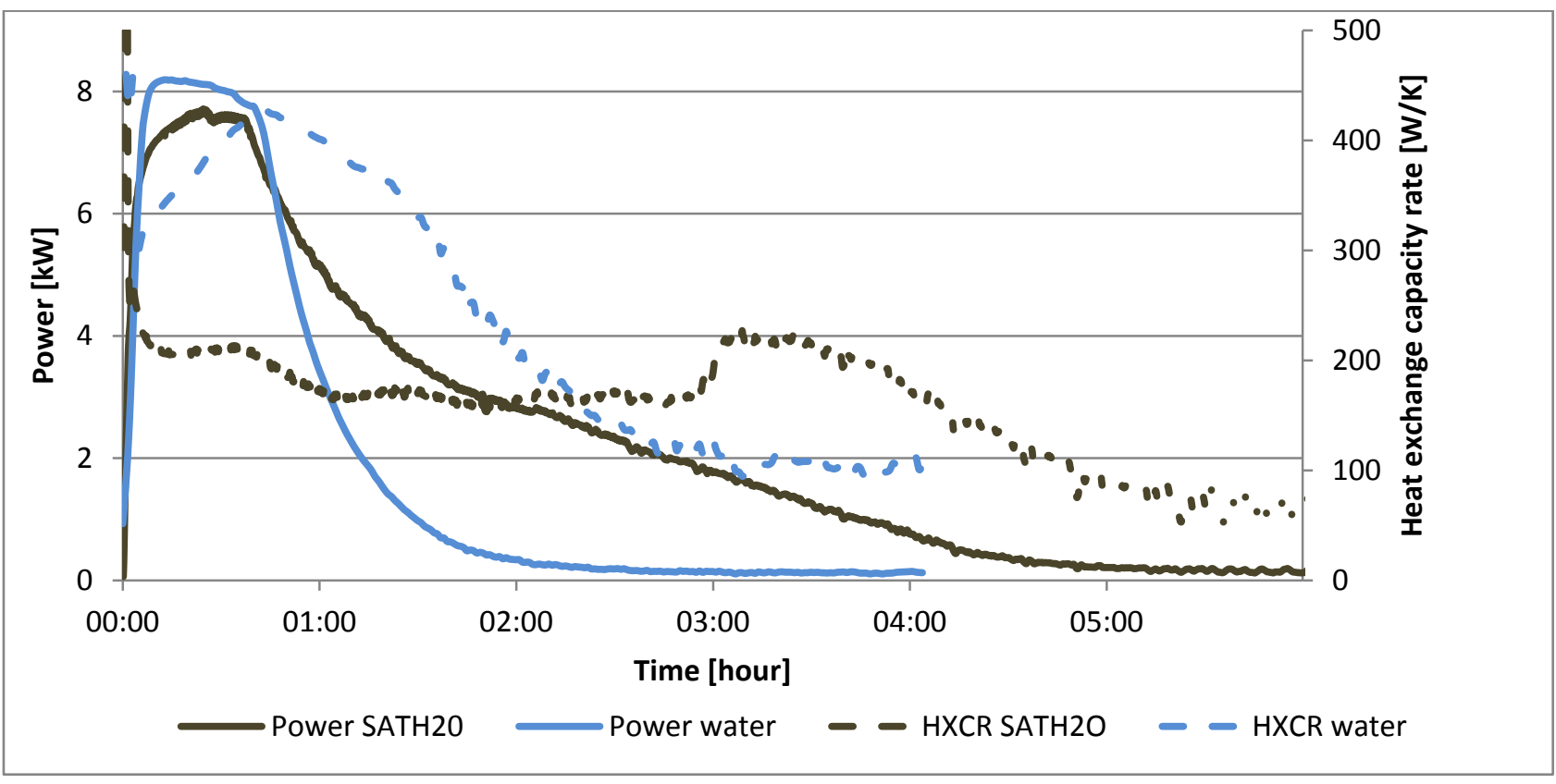

Figure 6. Typical charge powers and HXCRs for units with water and SATH20.

In Figure 6 can be seen, that the HXCR in the first hour of the charge was significantly higher for the unit with water compared to the unit with SATH2O, even though the charge powers were similar. This was due to a higher heat transfer by convection in the unit with water compared to the unit with SATH2O, in which the PCM was solid from the start. The power decreased earlier for the unit with water due to it being fully charged faster as a result of the lower heat capacity and a higher HXCR. At the third hour, the HXCR for the unit with SATH2O increased. At this time the last sensor on the outside of the tank had reached $58{ }^{\circ} \mathrm{C}$ which indicates that the SATH2O was fully melted. At this point no solid SATH2O remained and the heat transfer was dominated by convection. paraffin oil. The conditions for the charges, the heat contents and charge times are listed in Table 2. 
Table 2. Start and maximum storage temperature, flow rate, heating element power, inlet temperature, heat content and charge time for units with SATH2O and SATXC.

\begin{tabular}{|l|c|c|c|c|c|c|}
\hline $\begin{array}{l}\text { Storage } \\
\text { medium }\end{array}$ & Start temp. & Max temp. & Flow rate & Heating element & Heat content & Charge time \\
& $T_{\text {start }}$ & $T_{\max }$ & $\dot{V}$ & $\dot{Q} / T_{\text {in }}$ & $E_{\text {charge }}$ & $t$ \\
\hline SATH2O & $18.8{ }^{\circ} \mathrm{C}$ & $85.6{ }^{\circ} \mathrm{C}$ & $7.3 \mathrm{I} / \mathrm{min}$ & $6 \mathrm{~kW} / 87^{\circ} \mathrm{C}$ & $45.8 \mathrm{MJ}$ & $308 \mathrm{~min}$ \\
\hline SATXC + oil & $23.2^{\circ} \mathrm{C}$ & $90.8{ }^{\circ} \mathrm{C}$ & $7.4 \mathrm{I} / \mathrm{min}$ & $6 \mathrm{~kW} / 95^{\circ} \mathrm{C}$ & $50.1 \mathrm{MJ}$ & $376 \mathrm{~min}$ \\
\hline
\end{tabular}

Figure 7 shows the HXCR and power $\dot{Q}_{\text {charge }}$ for the charge period for the units filled with SATH2O and SATXC with oil.

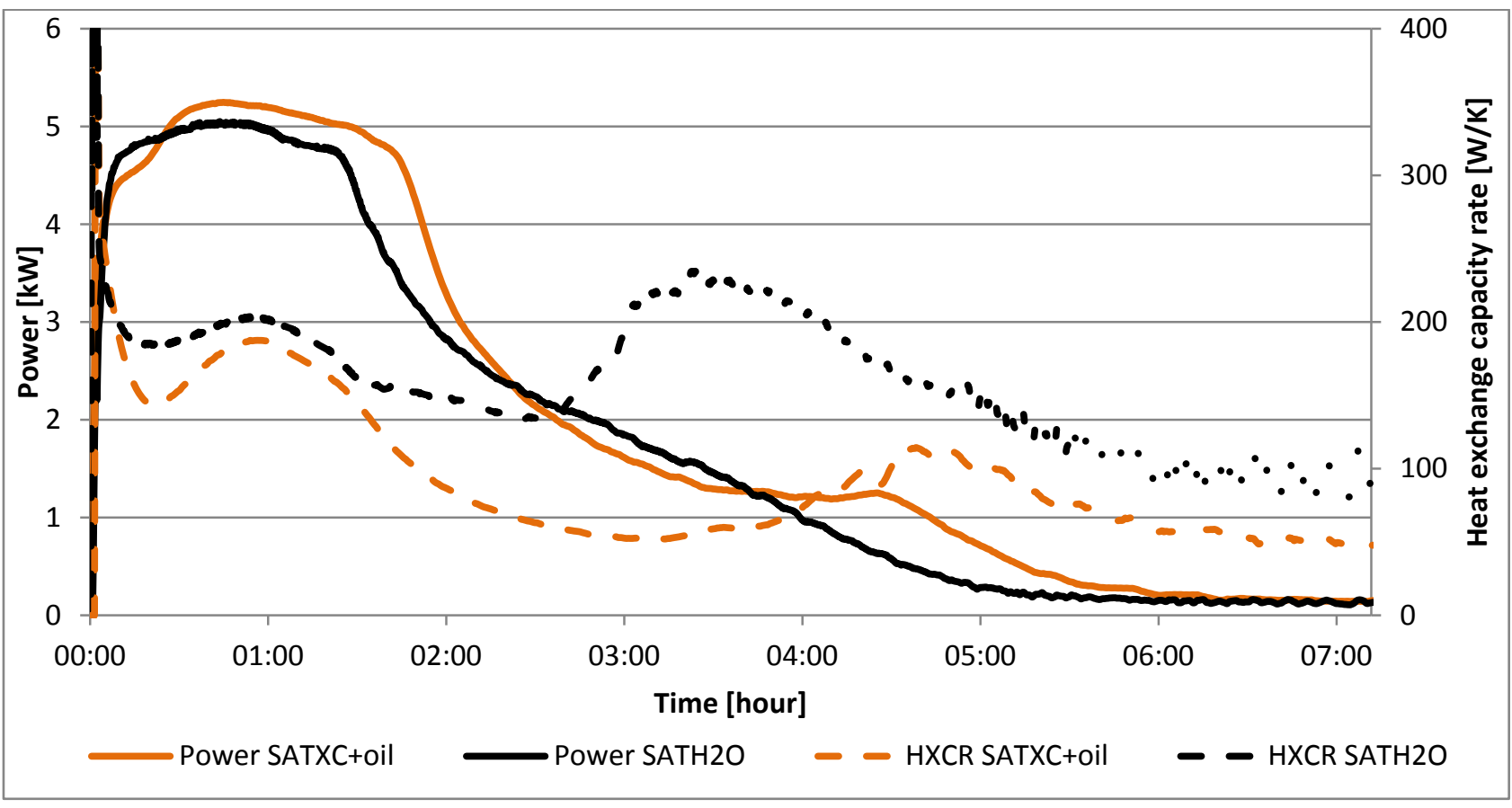

Figure 7. Typical charge powers and HXCRs for units with SATH2O and unit with SATXC with oil.

With similar conditions for charging, the HXCR for the unit with SATH2O was significantly higher compared to the unit with SATXC and oil. The heat content of the unit with thickened PCM was $9 \%$ higher for the applied temperature intervals but the charge time was $22 \%$ longer. This was due to the better heat transfer by convection in the unit without a thickening agent. Again, at the third hour there was an increase in HXCR for the unit with SATH2O due to increased heat transfer by convection in the fully melted PCM. This increase is much less evident and occurring later in the unit with SATXC due to the higher viscosity of the SATXC in the melted state.

The HXCRs for charging the unit with SATXC with and without one litre of paraffin oil was compared. The charge conditions, the heat contents and charge times are listed in Table 3.

Table 3. Start and maximum storage temperature, flow rate, heating element power, inlet temperature, heat content and charge time.

\begin{tabular}{|l|c|c|c|c|c|c|}
\hline Storage & Start temp. & Max temp. & Flow rate & Heating element & Heat content & Charge time \\
medium & $T_{\text {start }}$ & $T_{\max }$ & $\dot{V}$ & $\dot{Q} / T_{\text {in }}$ & $E_{\text {charge }}$ & $t$ \\
\hline
\end{tabular}




\begin{tabular}{|l|l|l|l|l|l|l|}
\hline SATXC & $21.5{ }^{\circ} \mathrm{C}$ & $90.4{ }^{\circ} \mathrm{C}$ & $13.7 \mathrm{I} / \mathrm{min}$ & $6 \mathrm{~kW} / 92^{\circ} \mathrm{C}$ & $50.9 \mathrm{MJ}$ & $395 \mathrm{~min}$ \\
\hline SATXC + oil & $20.8{ }^{\circ} \mathrm{C}$ & $90.8{ }^{\circ} \mathrm{C}$ & $13.7 \mathrm{I} / \mathrm{min}$ & $6 \mathrm{~kW} / 92^{\circ} \mathrm{C}$ & $51.3 \mathrm{MJ}$ & $377 \mathrm{~min}$ \\
\hline
\end{tabular}

The charge powers $\dot{Q}_{\text {charge }}[\mathrm{W}]$ and HXCRs for selected charges are displayed in Figure 8.

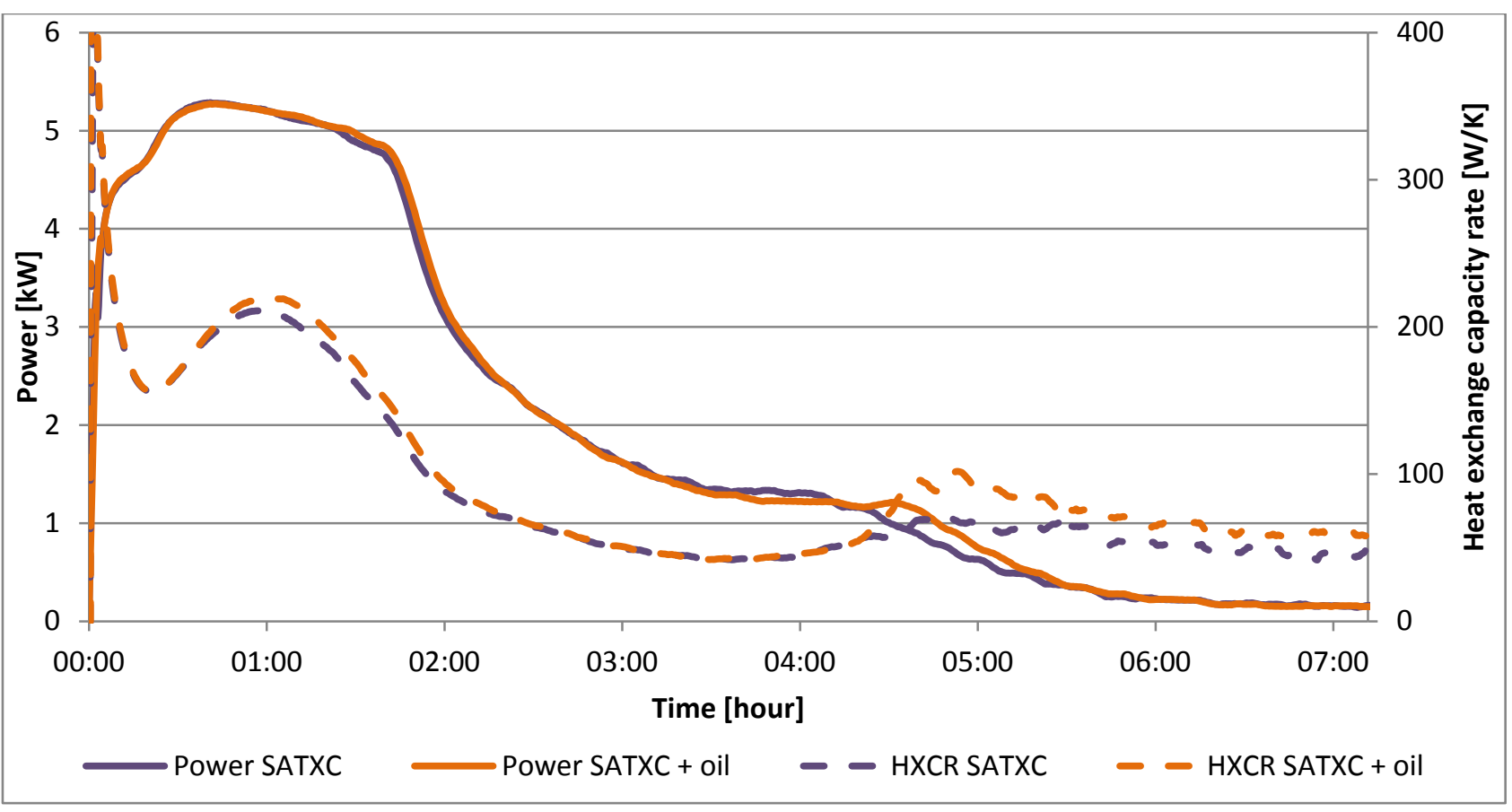

Figure 8. Charge powers and HXCRs for the unit with SATXC with and without 1 litre of paraffin oil.

Figure 8 shows a slight improvement of the HXCR by adding the one litre of paraffin oil. The effect was clearest from hour one to hour two of charging when the PCM was primary in the solid phase. In the last part of the charge temperature measurement uncertainties may cause the difference between the curves. After approximately $4 \mathrm{~h} 30$ all temperature sensor on the outer surfaces of the tanks had reached $58^{\circ} \mathrm{C}$. At this point the phase change was complete and the energy was transferred to the liquid PCM as sensible heat.

The flat units previously tested by Dannemand et al. [27] were tested under different test conditions, therefore a direct comparison of performance is not possible. For the units with thickening agents, the HXCR were typically below $200 \mathrm{~W} / \mathrm{K}$ in the majority of the charge periods for both designs with the higher values in the start of the charge and decreased during the period. Comparing charge conditions of the two differently designed units filled with SAT and extra water showed that the increase of the HXCR in the end on the charge period, where the PCM was fully melted, were a much higher percentagewise in the flat unit compared to the cylindrical unit. This indicates that the flat unit design better induces convection in the melted PCM.

\subsection{Discharge sensible heat}

After the stable hot period, the sensible heats of the units were discharged. This left the units with PCMs in a supercooled state when the solidification did not start spontaneously. The temperature of the units in the stable hot states, the inlet temperatures of the heat transfer fluid, the flow rates, the discharged heat and the discharge times for typical cycles with units with water, SATH2O and SATXC with oil are listed in Table 4. The discharge was considered complete when the average storage temperature was $0.5 \mathrm{~K}$ higher than the inlet temperature. Temperature intervals 
are listed for the inlet temperature $T_{i}$ because the temperature varied due to the response time of the thermostatic valve.

Table 4. Start storage temperature, inlet temperature, flow rate, discharged heat and discharge time for sensible heats.

\begin{tabular}{|l|c|c|c|c|c|}
\hline Storage medium & Start temp. & Inlet temp. & Flow rate & Discharged heat & Discharge time \\
& $T_{\max }$ & $T_{i}$ & $\dot{V}$ & $E_{\text {discharge }}$ & $t$ \\
\hline Water & $82.4^{\circ} \mathrm{C}$ & $25-20^{\circ} \mathrm{C}$ & $5.7 \mathrm{I} / \mathrm{min}$ & $25.3 \mathrm{MJ}$ & $177 \mathrm{~min}$ \\
\hline SATH2O & $85.5^{\circ} \mathrm{C}$ & $27-20^{\circ} \mathrm{C}$ & $5.7 \mathrm{I} / \mathrm{min}$ & $26.9 \mathrm{MJ}$ & $288 \mathrm{~min}$ \\
\hline SATXC + oil & $90.9^{\circ} \mathrm{C}$ & $27-24^{\circ} \mathrm{C}$ & $6.2 \mathrm{I} / \mathrm{min}$ & $26.3 \mathrm{MJ}$ & $370 \mathrm{~min}$ \\
\hline
\end{tabular}

298 The discharge powers and the HXCRs for the discharge periods can be seen in Figure 9.

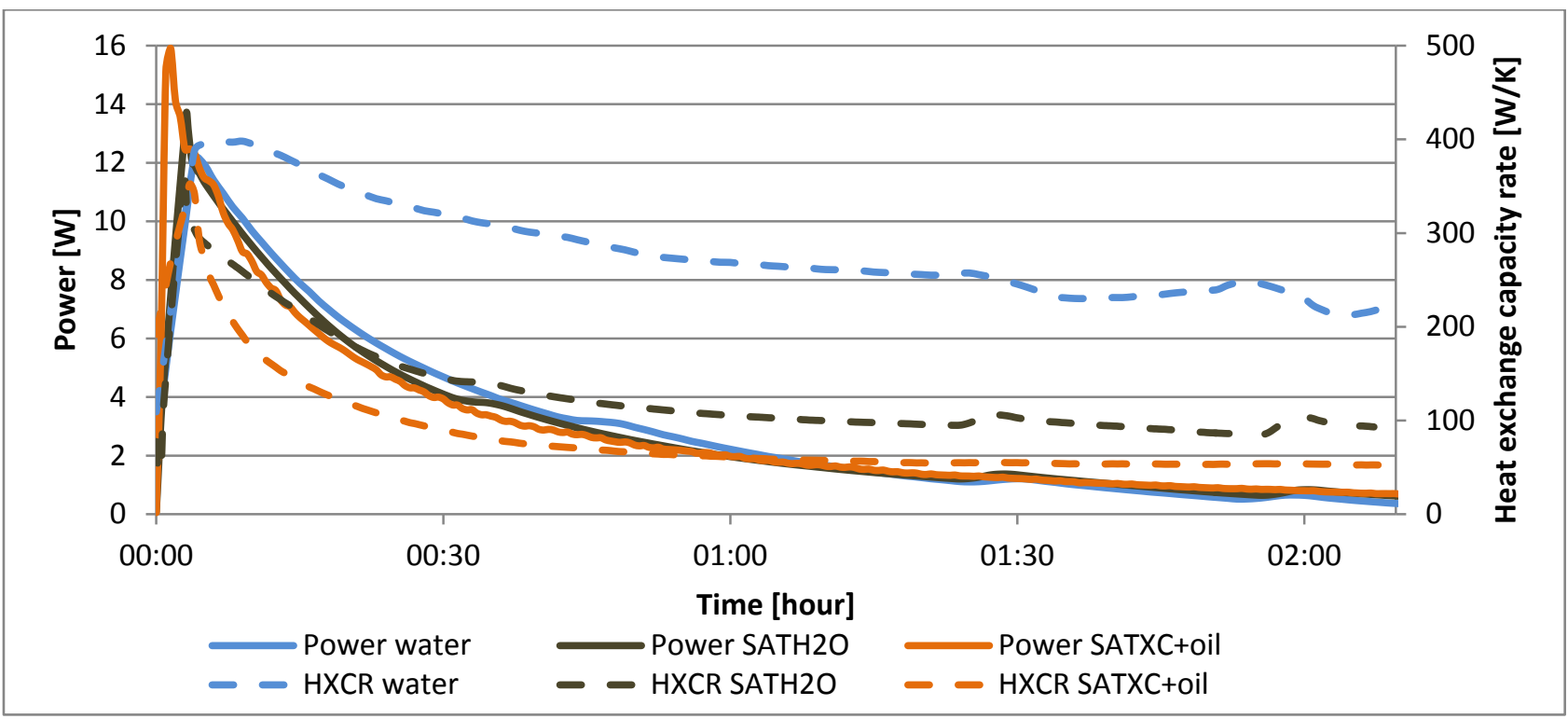

300 Figure 9. Typical discharge power and HXCR for the units with water, SATH2O and SATXC.

301 The majority of the heat was discharged during the first hour of discharge. The power and the HXCRs were the highest 302 for the unit with water during this period. The discharge power of the unit with SATXC with oil had a higher peak at 303 the beginning of the discharge due to a higher start storage temperature. The HXCR for the unit with SATXC was significantly lower compared to the unit with SATH2O. This was due to the higher viscosity of the thickened PCM which affected the heat transfer by convection. This is also reflected in the discharge times.

\subsection{Discharge latent heat}

307 After the sensible heats of the units with PCMs were discharged the PCMs were in supercooled states at ambient temperature. The solidification was initialized by slightly shaking the unit or by dropping a seed crystal into the PCM. After solidification the latent heat of fusion was discharged. The temperatures of the units in the supercooled states, the inlet temperatures of the heat transfer fluid, the flow rates, the discharged heats for typical cycles with units with SATH2O and SATXC with oil are listed in Table 5. 
Table 5. Start storage temperature, inlet temperature, flow rate and discharged heat for discharge of latent heat.

\begin{tabular}{|l|c|c|c|c|}
\hline Storage medium & Start temp. & Inlet temp. & Flow rate & Discharged heat \\
& $T_{\text {super }}$ & $T_{i}$ & $\dot{V}$ & $E_{\text {discharge }}$ \\
\hline SATH2O & $18.8^{\circ} \mathrm{C}$ & $27-20^{\circ} \mathrm{C}$ & $5.7 \mathrm{l} / \mathrm{min}$ & $16.7 \mathrm{MJ}$ \\
\hline SATXC + oil & $25.3^{\circ} \mathrm{C}$ & $27-24{ }^{\circ} \mathrm{C}$ & $5.7 \mathrm{I} / \mathrm{min}$ & $25.4 \mathrm{MJ}$ \\
\hline
\end{tabular}

The discharge powers and HXCRs for the discharge period can be seen in Figure 10.

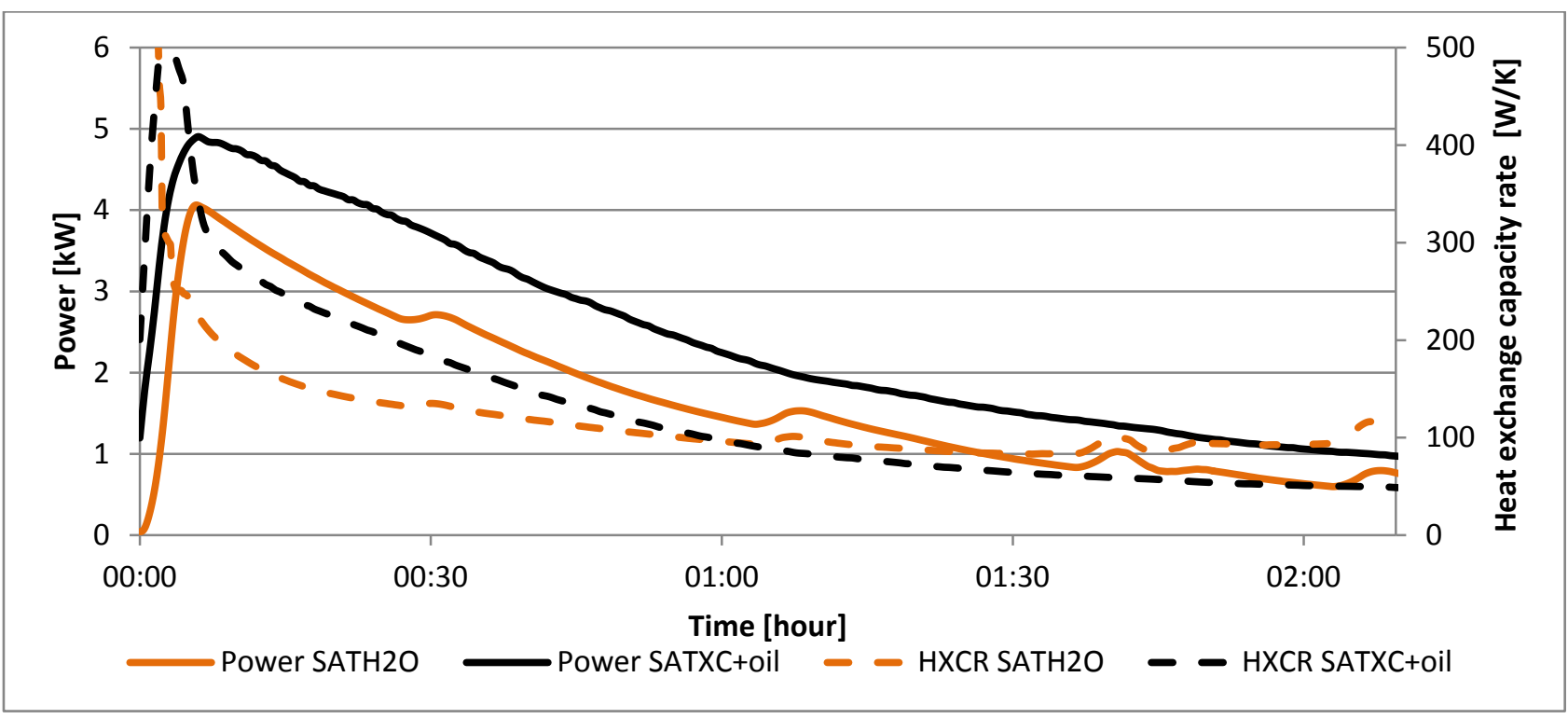

Figure 10. Typical discharge powers and HXCRs after solidification for units with SATH2O and SATXC.

Both the power and the HXCR were higher for the unit with SATXC compared to the unit with SATH2O. This was due to a higher heat content of the SATXC compared to the SATH2O. The thermal conductivity of the SATXC was assumed to be higher than for the SATH2O due to the addition of graphite powder and thereby also increasing the discharge power and HXCR. The higher storage temperature of the SATXC before solidification also resulted in a higher discharge power and heat content.

No significant difference was found when comparing discharge of sensible heat or latent heat from the unit with SATXC with or without one litre of paraffin oil. The amount of oil added was only $1-2 \%$ of the volume of the PCM. The density difference between the solid and liquid SAT is theoretically $12 \%$ [38]. A larger percentage of oil may have a better effect.

The flat unit tested by Dannemand et al. [27] showed a similar tendency for discharge powers with a peak in the beginning of the discharge period followed by a steadily decrease until the units were fully discharged.

\subsection{Discharge temperatures}

The temperature increases from inlet to outlet during the discharge of latent heat for selected cycles are displayed in 


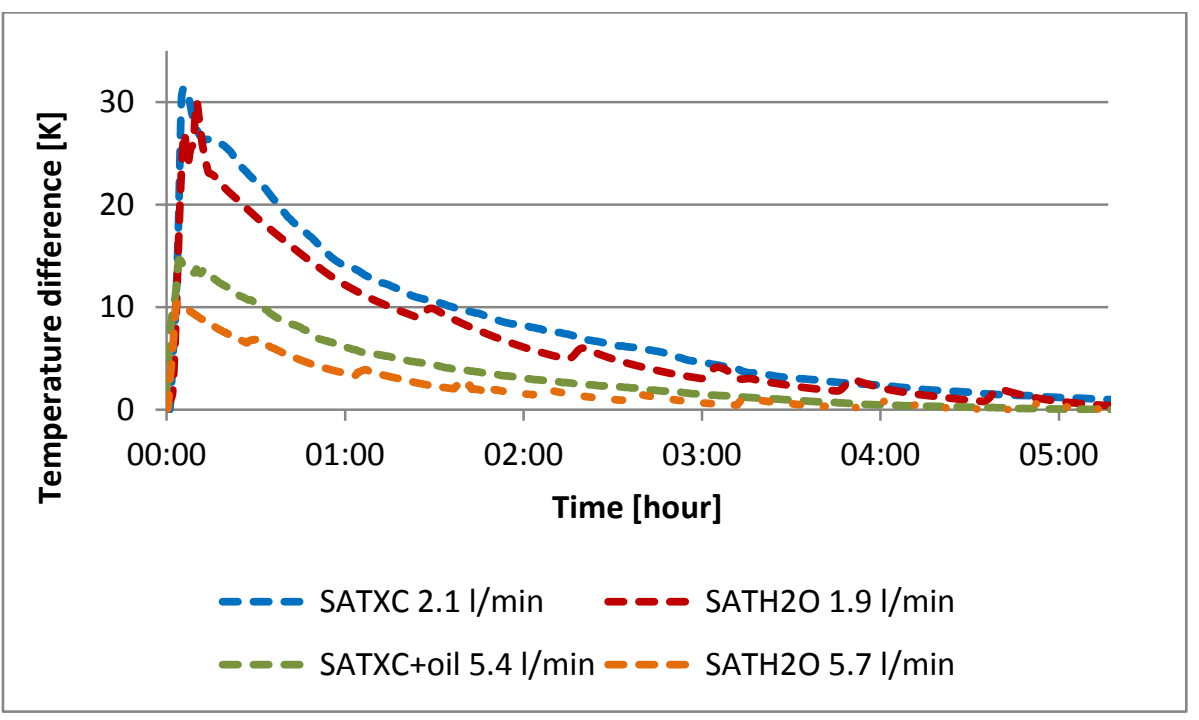

Figure 11. Temperature difference between inlet and outlet during discharge of latent heat.

The temperature increase of the heat transfer fluid during discharge was higher with lower flow rates. The unit with SATXC gave higher discharge temperatures compared to the unit with SATH2O at similar flow rates. With a discharge of $1.9 \mathrm{l} / \mathrm{min}$ and an inlet temperature of $22^{\circ} \mathrm{C}$, a maximum outlet temperature of $51{ }^{\circ} \mathrm{C}$ was reached at the start of the discharge of the unit with SATXC. The measured surface temperature of the unit with SATXC after solidification was 1$2 \mathrm{~K}$ higher compared to the unit with SATH2O. This indicates a higher PCM temperature after solidification in the SATXC.

The flat unit tested by Dannemand et al. [27] showed a similar tendency for discharge temperatures with the highest temperature increase in the beginning of the discharge followed by a steadily decrease towards the inlet temperature.

\subsection{Heat content and cycling stability of SAT composites}

The heat charged to the unit with SATH2O when heating from approximately $19{ }^{\circ} \mathrm{C}$ to $88^{\circ} \mathrm{C}$ was stable at $45-48 \mathrm{MJ}$ over the 17 test cycles. The heat discharged from the unit with SATH2O after solidification of the supercooled SATH2O at a temperature of $20-25{ }^{\circ} \mathrm{C}$ and discharging it back down to the same temperature was $20 \mathrm{MJ}$ in the first cycle and $16.3 \mathrm{MJ}$ in the $15^{\text {th }}$ test cycle. The heat charged into the unit with SATXC when heating from approximately $21^{\circ} \mathrm{C}$ to 91 ${ }^{\circ} \mathrm{C}$ was stable at 50 - $53 \mathrm{MJ}$ over the 40 test cycles. The heat discharged after solidification of the supercooled SATXC at $20-25{ }^{\circ} \mathrm{C}$ and discharging back down to the same temperature was stable at $24-26 \mathrm{MJ}$ for the test cycles where stable supercooled was achieved.

The heat content in the fully charged state was $9 \%$ higher in the unit with SATXC compared to the unit with SATH2O when including corrections for the slightly different the start, maximum and end temperatures. The discharged sensible heat was 1.5\% lower from the unit with SATXC compared to the unit with SATH2O. The discharged latent heat after solidification of the supercooled PCM was $20-36 \%$ higher for the unit with SATXC compared to the unit with SATH2O. 

and in Figure 15 for SATXC and compared to the theoretical values. The stable conditions where comparisons of theoretical and measured heat contents are valid are marked with circles.

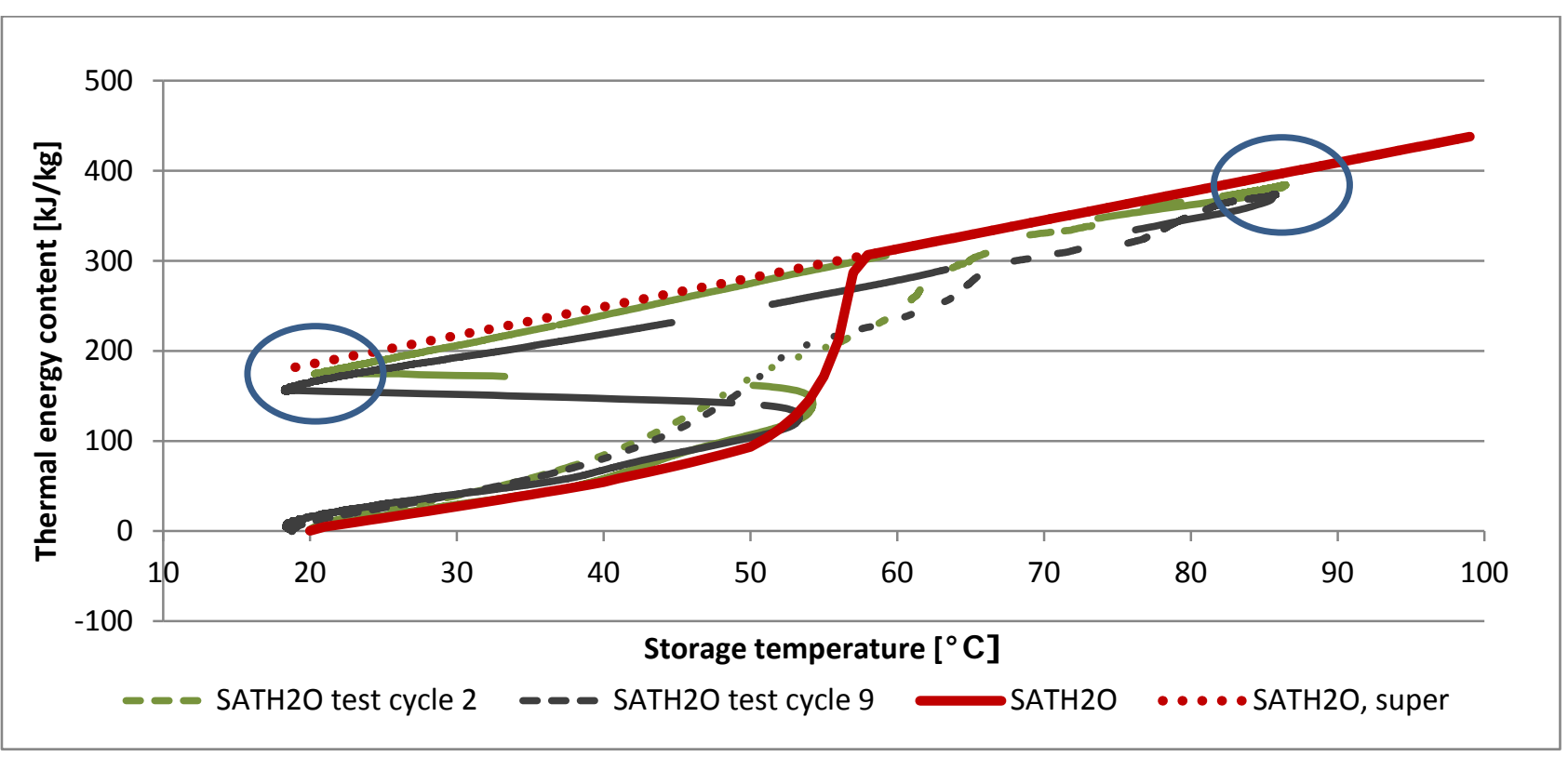

Figure 12. Measured heat content of SATH2O compared to theoretical heat content.

Figure 12 shows that the measured heat content in the $9^{\text {th }}$ test cycle with SATH2O was lower compared to the heat content for the $2^{\text {nd }}$ test cycle. The storage capacity of the SATH2O in the supercooled state at $20^{\circ} \mathrm{C}$ was $177 \mathrm{~kJ} / \mathrm{kg}$ in the first cycle decreasing to $140 \mathrm{~kJ} / \mathrm{kg}$ after 17 cycles, a decrease of $21 \%$.

Figure 13 and Figure 14 shows the top and bottom inspection windows of the unit after 17 cycles. There was a liquid solution layer of $20-22 \mathrm{~cm}$ in the top of the unit and a layer with whiter crystals in the bottom of the unit. This indicates a decreased salt concentration in the top and increased anhydrous salt at the bottom of the unit. The heat released after solidification of the supercooled SATH2O after a number of test cycles was decreased due to this phase separation.

In the research of Dannemand et al. where the flat unit was tested with $200 \mathrm{~kg}$ SAT with $9 \%$ extra water, the heat discharged after solidification the supercooled PCM at ambient temperature was $194 \mathrm{~kJ} / \mathrm{kg}$ in the first test cycle and $179 \mathrm{~kJ} / \mathrm{kg}$ after 14 test cycles [27][28]. This was a decrease of $8 \%$ from the first test cycle. This indicates that a tall unit is more likely to suffer from phase separation or that the higher water concentration in the SAT-water mixture better solved the phase separation. 


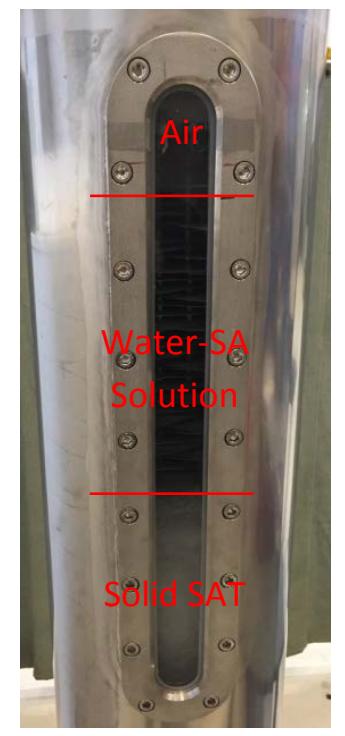

375 Figure 13. Top inspection window of unit with SATH2O.

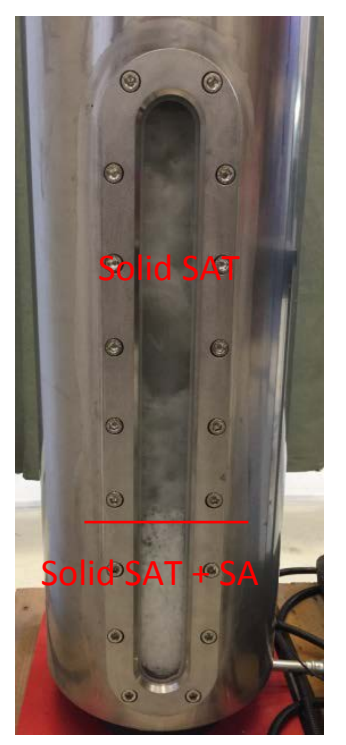

376

377 Figure 14. Bottom inspection window of unit with SATH2O. 


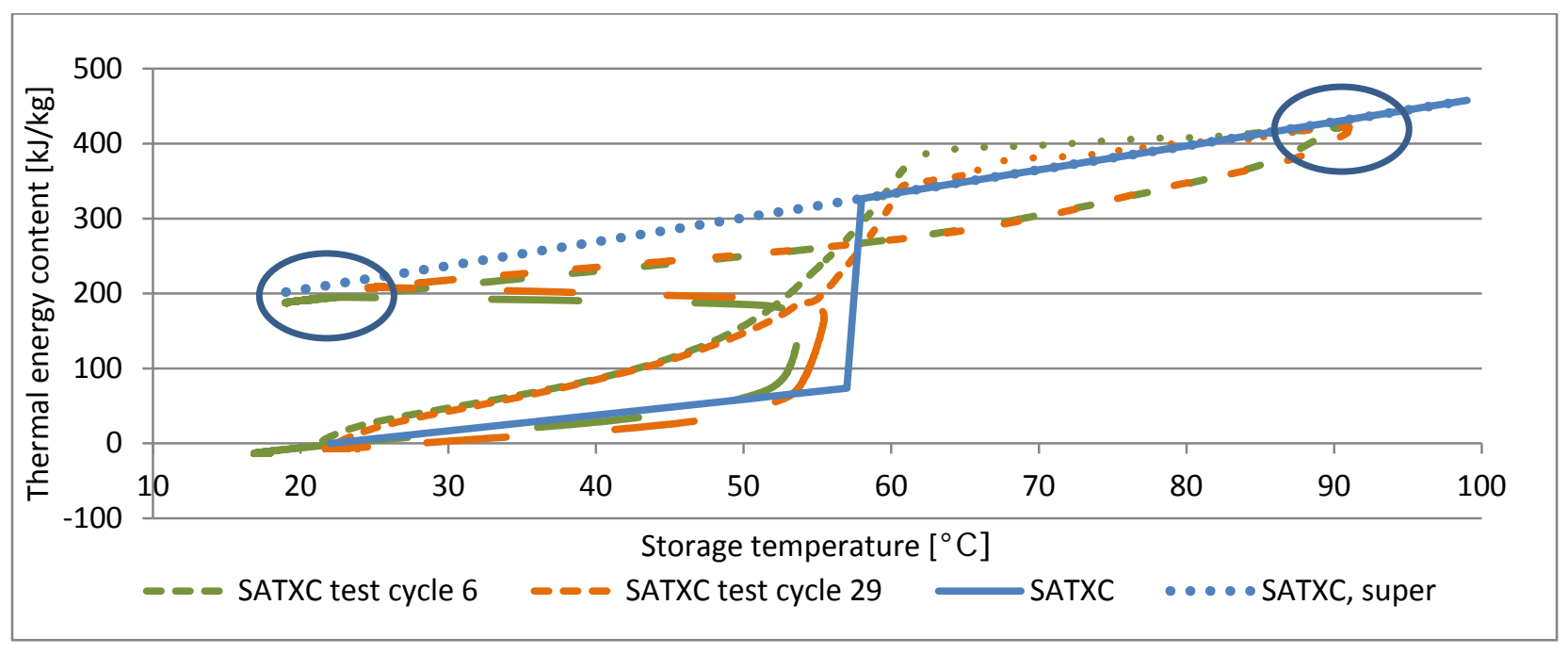

Figure 15. Measured heat content of SATXC compared to theoretical heat content.

Figure 15 shows that the measured heat content of the SATXC is close to the theoretical values and the heat contents were similar for the $6^{\text {th }}$ and $29^{\text {th }}$ test cycles. The storage capacity was $205-210 \mathrm{~kJ} / \mathrm{kg}$ of SATXC in the supercooled state at $20^{\circ} \mathrm{C}$ throughout the test cycles carried out. Dannemand et al. found in the investigations of the flat heat storage unit with SAT thickened with 1\% CMC a stable heat content of the supercooled PCM of $205 \mathrm{~kJ} / \mathrm{kg}$ over 6 test cycles [27].

\subsection{Supercooling stability}

The SATH2O solidified spontaneously 10 times during discharge in the 17 test cycles. The stable supercooled state was reached 7 times. Slightly pushing the unit initialized the crystallization. The crystallization started from the bottom. It is assumed that a torque at a crack or joint at the bottom of the PCM chamber caused the starting of the solidification in a similar way as when flexing a metal disc in the hand warmers is a method for initializing crystallization [42]. The unit with SATXC solidified spontaneously 34 times of the 40 test cycles. In 6 cycles the unit reached a supercooled state at ambient temperature, it was activated manually by dropping a seed crystal into the PCM or shaking the unit. Three times the spontaneous solidification started from the bottom in the unit with SATXC, 22 times it started from the top and 9 times it was not possible to determine the starting point of crystallization. Crystallization starting from the bottom could be for the same reason as for the unit with SATH2O. Crystallization starting from the top may indicate that the solution for solving the expansion and contraction of the PCM by an air filter or expansion vessel may not be a viable solution. The solution did however seem to be working for the unit with SATH2O. Supercooled periods up to two days were achieved for the unit with SATXC with the air filter in two test cycles. However, the semi-open approach may lead to the loss of water vapour from the PCM chamber resulting in a change in PCM mixture composition and is therefore not a recommended solution.

Some of the spontaneous solidifications of the SAT mixtures were most likely caused by the design of the inner surfaces of the PCM chamber. It is recommended that the PCM chamber is designed with all inner surfaced being completely smooth with no cracks where surfaces are joining and no penetrations of the chamber wall with tubes where the SAT is in contact. Such areas pose a risk of spontaneous crystallization when crystals are trapped under high pressure and later released into the supercooled PCM if movement occurs. 
The method for solving the expansion and contraction of the PCM was likewise not completely solved. Integrating a flexibility of the storage chamber itself may be a solution to avoid the external expansion. This could be a flexible membrane in the top of the PCM chamber or it could be by making the PCM chamber of a material which is relatively flexible for example a plastic material. Heat exchanger tubes could enter and exit in the top of the unit above the PCM.

\section{Conclusions}

Cylindrical heat storage units with water and with composites of SAT were experimentally investigated. It was found that the heat exchange capacity rates for the units with PCMs were lower than for the unit with water. The heat exchange capacity rate of the unit with SAT with $0.5 \%$ Xanthan rubber and $4.4 \%$ graphite was lower compared to the unit with SAT with $6.4 \%$ extra water during charge. This was due to limited convection in the thickened PCM and resulted in a longer charge time. One litre of paraffin oil added to the PCM chamber gave a minor improvement of the heat exchange capacity rate during charge.

The heat discharged after solidification of the supercooled SAT with extra water at ambient temperature was 177 $\mathrm{kJ} / \mathrm{kg}$ in the first cycle decreasing to $140 \mathrm{~kJ} / \mathrm{kg}$ after 17 test cycles. Phase separation was visually observed in the unit and the reason for the decrease. For the applied test conditions, phase separation of SAT was not solved by adding extra water. Stable supercooling to ambient temperatures was achieved in 7 out of 17 test cycles with the unit with SAT with extra water. The crystallization started from the bottom by slightly shaking the unit most likely due to the design of inner surfaces of the PCM chamber of the unit.

The heat discharged after solidification of the supercooled SAT with Xanthan rubber and graphite powder at ambient temperature was stable around $205-210 \mathrm{~kJ} / \mathrm{kg}$ over the 40 test cycles carried out. Stable supercooling to ambient temperatures was achieved in 6 out of 40 test cycles in the unit with SAT with Xanthan rubber and graphite powder. The spontaneous crystallization started mostly from the top of the PCM. Higher discharge powers, heat exchange capacity rates and temperatures were obtained after solidification of the unit with supercooled SAT with Xanthan rubber and graphite powder compared to the unit with SAT with extra water.

Overall, these investigations have shown that the principle of utilizing stable supercooling for partly loss-free heat storage can work. SAT thickened with $0.5 \%$ Xanthan rubber did not suffer from phase separation over repeated charge and discharge cycles in a unit with a height of $1.5 \mathrm{~m}$. However, accommodating for the expansion and contraction of the PCM during melting needs further research in order to always achieve stable supercooling.

\section{Acknowledgement}

The research was partly funded by H.M. Heizkörper GmbH \& Co. KG who developed the heat storage unit prototypes and partly funded by the Danish Energy Agency supporting the joint IEA SHC Task 42/ ECES Annex 29 programme on Compact Thermal Energy Storage, Grant no. 64012-0220.

\section{Nomenclature}

$c_{p}$

$C_{\text {tank }}$

$E_{\text {charge }}$

Elischarge specific heat capacity

heat capacity of storage tank material measured heat content after charge measured discharged heat
$[\mathrm{kJ} / \mathrm{kg} \mathrm{K}]$

$[\mathrm{kJ} / \mathrm{K}]$

[J]

[J] 


$\begin{array}{llll}442 & E_{P C M} & \text { heat capacity of PCM } & {[\mathrm{kJ} / \mathrm{kg}]} \\ 443 & H_{\text {loss }} & \text { heat loss coefficient } & {[\mathrm{W} / \mathrm{K}]} \\ 444 & H X C R & \text { heat exchange capacity rate } & {[\mathrm{W} / \mathrm{K}]} \\ 445 & m & \text { mass } & {[\mathrm{kg}]} \\ 446 & \dot{Q} & \text { charge/discharge power } & {[\mathrm{W}]} \\ 447 & t & \text { time } & {[\mathrm{s}]} \\ 448 & T_{\text {amb }} & \text { ambient temperature } & {\left[{ }^{\circ} \mathrm{C}\right]} \\ 449 & T_{i} & \text { inlet temperature } & {\left[{ }^{\circ} \mathrm{C}\right]} \\ 450 & T_{\text {max }} & \text { maximum storage temperature } & {\left[{ }^{\circ} \mathrm{C}\right]} \\ 451 & T_{0} & \text { outlet temperature } & {\left[{ }^{\circ} \mathrm{C}\right]} \\ 452 & T_{s} & \text { storage mean temperature } & {\left[{ }^{\circ} \mathrm{C}\right]} \\ 453 & T_{\text {start }} & \text { storage temperature at the beginning of a cycle } & {\left[{ }^{\circ} \mathrm{C}\right]} \\ 454 & T_{\text {super }} & \text { temperature of the storage with the PCM in supercooled state } & {\left[{ }^{\circ} \mathrm{C}\right]} \\ 455 & \dot{V} & \text { volume flow rate } & {\left[\mathrm{m}^{3} / \mathrm{h}\right]} \\ 456 & \rho & \text { density } & {\left[\mathrm{kg} / \mathrm{m}^{3}\right]} \\ 457 & \text { Abbreviations } & & \\ 458 & \text { SAT } & & \\ 459 & \text { SATH2O } & & \\ 460 & \text { SATXC } & \text { sodium acetate trihydrate } & \\ 461 & \text { PCM } & \text { mixture of } 93.6 \% \text { SAT and } 6.4 \% \text { water } & \\ 462 & \text { CMC } & \text { mixture of } 95.1 \% \text { SAT, } 0.5 \% \text { Xanthan rubber and } 4.4 \% \text { graphite powder }\end{array}$

[1] Najafian A, Haghighat F, Moreau A. Integration of PCM in Domestic Hot Water Tanks: Optimization for Shifting Peak Demand. Energy Build 2015;106:59-64. doi:10.1016/j.enbuild.2015.05.036.

[2] Sharma SD, Sagara K. Latent Heat Storage Materials and Systems: A Review. Int J Green Energy 2005;2:1-56. doi:10.1081/GE-200051299.

[3] Nkwetta DN, Vouillamoz P-E, Haghighat F, El-Mankibi M, Moreau A, Daoud A. Impact of phase change materials types and positioning on hot water tank thermal performance: Using measured water demand profile. Appl Therm Eng 2014;67:460-8. doi:10.1016/j.applthermaleng.2014.03.051.

[4] Zalba B, Marín JM, Cabeza LF, Mehling H. Review on thermal energy storage with phase change: materials, heat transfer analysis and applications. Appl Therm Eng 2003;23:251-83. doi:10.1016/S1359-4311(02)001928.

[5] Johansen JB, Dannemand M, Kong W, Fan J, Dragsted J, Furbo S. Thermal Conductivity Enhancement of Sodium Acetate Trihydrate by Adding Graphite Powder and the Effect on Stability of Supercooling. Energy Procedia 2015;70:249-56. doi:10.1016/j.egypro.2015.02.121.

[6] Sandnes B, Rekstad J. Supercooling salt hydrates: Stored enthalpy as a function of temperature. Sol Energy 2006;80:616-25. doi:10.1016/j.solener.2004.11.014.

[7] López-Navarro A, Biosca-Taronger J, Corberán JM, Peñalosa C, Lázaro A, Dolado P, et al. Performance characterization of a PCM storage tank. Appl Energy 2014;119:151-62. doi:10.1016/j.apenergy.2013.12.041.

[8] Novo A V, Bayon JR, Castro-Fresno D, Rodriguez-Hernandez J. Review of seasonal heat storage in large basins: Water tanks and gravel-water pits. Appl Energy 2010;87:390-7. doi:10.1016/j.apenergy.2009.06.033. 
[10] Sharif MKA, Al-Abidi AA, Mat S, Sopian K, Ruslan MH, Sulaiman MY, et al. Review of the application of phase change material for heating and domestic hot water systems. Renew Sustain Energy Rev 2015;42:557-68. doi:10.1016/j.rser.2014.09.034.

[11] Xu J, Wang RZ, Li Y. A review of available technologies for seasonal thermal energy storage. Sol Energy 2013;103:610-38. doi:10.1016/j.solener.2013.06.006.

[12] Pinel P, Cruickshank CA, Beausoleil-Morrison I, Wills A. A review of available methods for seasonal storage of solar thermal energy in residential applications. Renew Sustain Energy Rev 2011;15:3341-59. doi:10.1016/j.rser.2011.04.013.

[13] Persson J, Westermark M. Low-energy buildings and seasonal thermal energy storages from a behavioral economics perspective. Appl Energy 2013;112:975-80. doi:10.1016/j.apenergy.2013.03.047.

[14] Colclough S, McGrath T. Net energy analysis of a solar combi system with Seasonal Thermal Energy Store. Appl Energy 2015;147:611-6. doi:10.1016/j.apenergy.2015.02.088.

[15] Dannemand M, Schultz JM, Johansen JB, Furbo S. Long term thermal energy storage with stable supercooled sodium acetate trihydrate. Appl Therm Eng 2015;91:671-8. doi:10.1016/j.applthermaleng.2015.08.055.

[16] Lane GA. Solar heat storage latent heat material Vol 1. Boca Raton, Florida, United States: CRC; 1983.

[17] Kimura H, Kai J. Phase change stability of sodium acetate trihydrate and its mixtures. Sol Energy 1985;35:52734. doi:10.1016/0038-092X(85)90121-5.

[18] Cabeza LF, Svensson G, Hiebler S, Mehling H. Thermal performance of sodium acetate trihydrate thickened with different materials as phase change energy storage material. Appl Therm Eng 2003;23:1697-704. doi:10.1016/S1359-4311(03)00107-8.

[19] Furbo S, Svendsen S. Report on heat storage in a solar heating system using salt hydrates. Kgs. Lyngby, Denmark: 1977.

[20] Farid MM, Khudhair AM, Razack SAK, Al-Hallaj S. A review on phase change energy storage: materials and applications. Energy Convers Manag 2004;45:1597-615. doi:10.1016/j.enconman.2003.09.015.

[21] Meisingset KK, Grønvold F. Thermodynamic properties and phase transitions of salt hydrates between 270 and

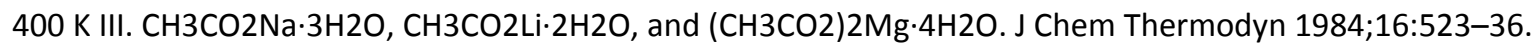
doi:10.1016/0021-9614(84)90003-X.

[22] Sun X, Zhang Q, Medina MA, Lee KO. Experimental observations on the heat transfer enhancement caused by natural convection during melting of solid-liquid phase change materials (PCMs). Appl Energy 2016;162:145361. doi:10.1016/j.apenergy.2015.03.078.

[23] Ryu HW, Woo SW, Shin BC, Kim SD. Prevention of supercooling and stabilization of inorganic salt hydrates as latent heat storage materials. Sol Energy Mater Sol Cells 1992;27:161-72. doi:10.1016/0927-0248(92)90117-8.

[24] Garay Ramirez BML, Glorieux C, Martin Martinez ES, Flores Cuautle JJA. Tuning of thermal properties of sodium acetate trihydrate by blending with polymer and silver nanoparticles. Appl Therm Eng 2013;61:83844. doi:10.1016/j.applthermaleng.2013.09.049.

[25] Hu P, Lu D-J, Fan X-Y, Zhou X, Chen Z-S. Phase change performance of sodium acetate trihydrate with AlN nanoparticles and CMC. Sol Energy Mater Sol Cells 2011;95:2645-9. doi:10.1016/j.solmat.2011.05.025.

[26] Shin HK, Park M, Kim H-Y, Park S-J. Thermal property and latent heat energy storage behavior of sodium acetate trihydrate composites containing expanded graphite and carboxymethyl cellulose for phase change materials. Appl Therm Eng 2015;75:978-83. doi:10.1016/j.applthermaleng.2014.10.035.

[27] Dannemand M, Dragsted J, Fan J, Johansen JB, Kong W, Furbo S. Experimental investigations on prototype heat storage units utilizing stable supercooling of sodium acetate trihydrate mixtures. Appl Energy 2016;169:72-80. doi:10.1016/j.apenergy.2016.02.038. 
Based on Stable Supercooling of Sodium Acetate Trihydrate. Energy Procedia, vol. 70, Elsevier B.V.; 2015, p. 172-81. doi:10.1016/j.egypro.2015.02.113.

[29] Medrano M, Yilmaz MO, Nogués M, Martorell I, Roca J, Cabeza LF. Experimental evaluation of commercial heat exchangers for use as PCM thermal storage systems. Appl Energy 2009;86:2047-55. doi:10.1016/j.apenergy.2009.01.014.

[30] Chiu JNW, Martin V. Submerged finned heat exchanger latent heat storage design and its experimental verification. Appl Energy 2012;93:507-16. doi:10.1016/j.apenergy.2011.12.019.

[31] Sari A, Karaipekli A. Thermal conductivity and latent heat thermal energy storage characteristics of paraffin/expanded graphite composite as phase change material. Appl Therm Eng 2007;27:1271-7. doi:10.1016/j.applthermaleng.2006.11.004.

[32] Kousksou T, Bruel P, Jamil A, El Rhafiki T, Zeraouli Y. Energy storage: Applications and challenges. Sol Energy Mater Sol Cells 2014;120:59-80. doi:10.1016/j.solmat.2013.08.015.

[33] Py X, Olives R, Mauran S. Paraffin/porous-graphite-matrix composite as a high and constant power thermal storage material. Int J Heat Mass Transf 2001;44:2727-37. doi:10.1016/S0017-9310(00)00309-4.

[34] Mills A, Farid M, Selman JR, Al-Hallaj S. Thermal conductivity enhancement of phase change materials using a graphite matrix. Appl Therm Eng 2006;26:1652-61. doi:10.1016/j.applthermaleng.2005.11.022.

[35] Zhang P, Xiao X, Ma ZW. A review of the composite phase change materials: Fabrication, characterization, mathematical modeling and application to performance enhancement. Appl Energy 2016;165:472-510. doi:10.1016/j.apenergy.2015.12.043.

[36] Dannemand M, Johansen JB, Furbo S. Solidification Behavior and Thermal Conductivity of Bulk Sodium Acetate Trihydrate Composites with Thickening Agents and Graphite. Sol Energy Mater Sol Cells 2016;145:287-95. doi:10.1016/j.solmat.2015.10.038.

[37] Industrie anzeiger n.d. http://www.industrieanzeiger.de/technik/-/article/32571342/37619152 (accessed October 22, 2015).

[38] Lane G. Solar heat storage latent heat material Vol 2. Boca Raton, Florida, United States: CRC; 1986.

[39] Furbo S. Heat Storage for Solar Heating Systems, Educational Note, ISSN 1396-4046. Kgs. Lyngby, Denmark: BYG.DTU; 2005.

[40] Cengel YA. Heat Transfer: A Practical Approach. 2nd ed. McGraw-Hill; 2003.

[41] Araki N, Futamura M, Makino A, Shibata H. Measurements of Thermophysical Properties of Sodium Acetate Hydrate. Internaltional J Thermophys 1995;16:1455-66. doi:10.1007/BF02083553.

[42] Rogerson MA, Cardoso SSS. Solidification in Heat Packs : III . Metallic Trigger. AIChE J 2003;49:522-9. doi:10.1002/aic.690490222. 